\title{
Numerical Simulation of Thermo Mechanical Fatigue Phenomenom and Damage Evolution Bihaviour 5182 H111 Aluminium Alloy
}

\author{
Abdelouahid El Amri ${ }^{1, ~ *}$, Mounir El Yakhloufi haddou ${ }^{1}$, Issam hanafi ${ }^{2}$, Francisco Mata Cabrera ${ }^{3}$ \\ ${ }^{1}$ Condensed matter, radiation and numerical simulation laboratory, Faculty of Sciences, Tetouan, Morocco \\ ${ }^{2}$ National School of Applied Sciences d'Al Hoceima (ENSAH), Hoceima, Morocco \\ ${ }^{3}$ University polytechnic School of Mining and Industrial Engineering of Almaden, Almaden, Spain \\ Email address: \\ Abdelouahid26@gmail.com (A. E. Amri)
}

\section{To cite this article:}

Abdelouahid El Amri, Mounir El Yakhloufi haddou, Issam hanafi, Francisco Mata Cabrera. Numerical Simulation of Thermo Mechanical Fatigue Phenomenom and Dammage Evolution Bihaviour 5182 H111 Aluminium Alloy. International Journal of Materials Science and Applications. Vol. 4, No. 4, 2015, pp. 272-276. doi: 10.11648/j.ijmsa.20150404.18

\begin{abstract}
The paper present results of a numerical modelling of ductile fracture and failure of elements made of 5182H111 aluminum alloy subjected to dynamic traction. The analysis was performed using Johnson-Cook model based ABAQUS software. The infrared thermography was used to quantify deformation localization zones, also to relate the temperature changes of the specimen, continuously recorded by thermography, with the load extension diagram. The aim of the research was to specify and test the mechanical properties during numerical simulation. The experimental test results for the mechanical properties of the studies are presented with a large description of the testing facilities. The test results were used to determine the temperature dependencies of the mechanical properties, yield strength, modulus of elasticity and thermal elongation.
\end{abstract}

Keywords: Mechanical Properties, Material Fatigue, Damage, Aluminum Alloy, Johnson-Cook Model

\section{Introduction}

Ductile fracture is a geometry dependent event, whereas the fracture toughness or ductility of a material can not be directly transferred from one geometry to another. It depends on variation of geometry constraint level, therefore conventional fracture mechanics parameters. Ductile fracture process is controlled by nucleation, growth and coalescence of micro voids, so it is natural to link material fracture behavior to the parameters that describe the evolution of micro voids rather than conventional global fracture Parameters [1]. Damage parameter is not incorporated into the constitutive equation and it is assumed that presence of voids does not significantly alter the behavior of the material. The von Mises criterion is most frequently used as yield criterion in uncoupled models, Damage parameter is incorporated into constitutive equation and crack growth simulation is automatically performed using a complete deterioration of elements in front of the crack tip [2].

For ductile metallic alloys, fatigue failure can occur at stress levels that are significantly lower than the yield strength. One of the most widely used models is Johnson-
Cook model for ductile materials. This model describing fatigue behavior of $5182 \mathrm{H} 111$ Aluminium alloy under cyclic loading and their applicability for modeling of low-cyclefatigue are discussed in this report. Numerical simulation has been used to study mechanical properties of material such as the tensile strength, the yield strength and Young's modulus depend the temperature because Young's modulus of some tempered steels increases slightly at mid temperatures before decreasing at high temperature on mechanical properties is linked to transformations of the material structure due to various processes[3 - 7]. In order to describe the cyclic behavior of the material for analysis with finite element method (FEM) based analysis code ABAQUS, the test data, i.e. stress-strain curves, have to be processed.

The aim of this study is to simulate the region of the specimen in which the cracks, causing the fracture of the specimen, will occur first of all other regions. To do this, we use real-time processing of the Tis of the specimen taken by a most widely used ( in industry).

Computer simulation has become reliable and acceptable in the metal forming industry since the 1980's. Metal forming analysis can be performed in tree modeling scales [5]. The 
first scale is the global modeling, which only predicts process loads or work. Analytical methods are used for this purpose. Local scale analysis is used to estimate the thermomechanical variables such as strain, strain rate, and temperature.

Johnson [6] states that experimental work used to teach metal forming shows an important feature when we analyze the great development observed in the numerical simulation of process, mainly the finite element method according to the increasing of these capacity and commercial software must be accompanied by a consistent practical learning.

\section{Experimental Setup}

The experimental setup for testing the tensile feature of specimen is illustrated in fig.1. Tensile testing and thermographic measurements were performed simultaneously. The testing of specimens was carried out on the electromechanical testing machine HOYTON TN-D, with the maximum displacement $210 \mathrm{~mm}$ and the strain control at room temperature.

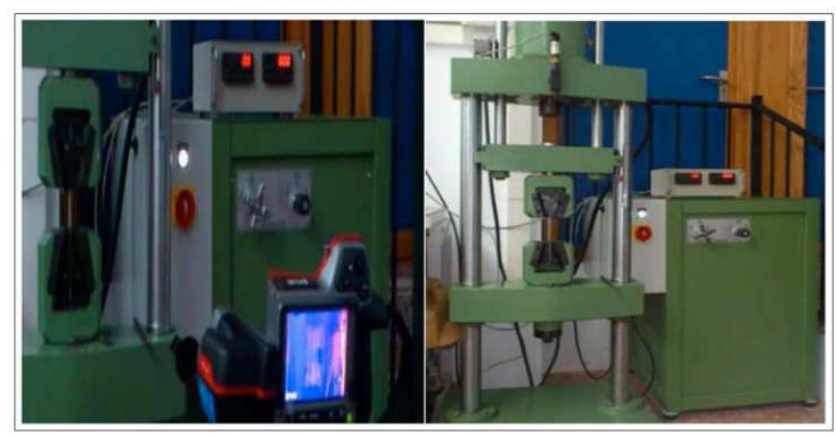

Figure 1. Tension test equipment.
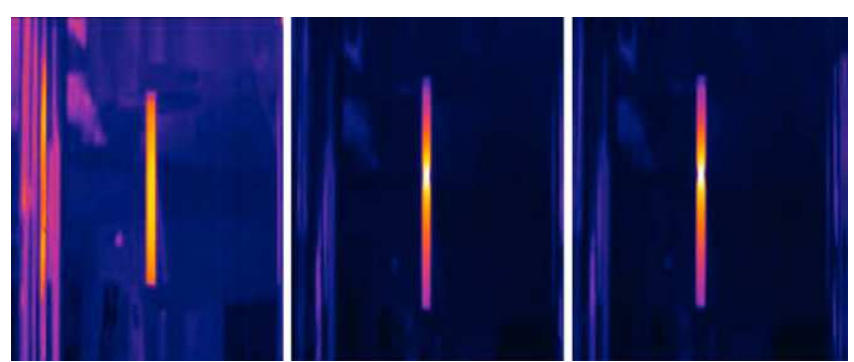

Figure 2. Infrared thermography images sequence of specimens during tensile loading.

The extension was registered using a double extensometer. The precision of the extensometer measurement is \pm 0.001 $\mathrm{mm}$. the therma CAM FLIR T335 infrared camera has been used for recording thermograms. The camera resolution is $320 \times 240$ pixels. The thermal measurement is performed at a frequency of $150 \mathrm{~Hz}$. It was positioned at a distance of $0.5 \mathrm{~m}$ from the sample surface. The camera sensitivity is $50 \mathrm{mK}$ at $30{ }^{\circ} \mathrm{C}$.the camera is provided with the automatic correction of emissivity and atmospheric transmission based on the distance, atmospheric temperature and relative humidity. It simultaneously makes video and thermographic recording or tracks.
The FLIR Quick Report 1.2 SP2 is capable of measuring temperature at sports, on lines and in select areas of various shapes and dimensions, as well as of showing isotherms using the gradation of grey or the palette of various colours and shades.

\section{Failure Model}

To get a more complete understanding of the Mechanical properties of material during testing, numerical simulations of the aluminum $5182 \mathrm{H} 111$ alloy were performed. This is an approach, complementary to the experimental method describing by [7], to evaluate thermal loads at different locations on the surface as well as within the specimen. The latter is quite difficult to achieve from an experimental point of view. The numerical analysis using the ABAQUS, explicit dynamic finite element software, was made in two steps, in order to develop and implement strain rate sensitive constitutive models. First, thermal analysis was performed to reproduce the surface thermal loads and to obtain the temperature evolution in the specimen. Second, a mechanical analysis was performed, using a Johnson-Cook model. Here, the numerical simulation methodology assumes a weak coupling between thermal and mechanical analyses. Due to the axisymmetrical geometry of the specimen, only a quarter of the specimen is meshed with four node rectangular axisymmetric elements and used in the calculations. The sample geometry and the axisymmetrical meshing is shown in Fig. 3. From the numerical simulations, temperature-strain loops at several locations in the specimen were obtained, and they were compared to those from the experimental tests.

Historically, the finite Element Method (FEM) has predominantly been used for modeling EFM [8].

\subsection{Johnson-Cook Failure Model}

The Johnson-Cook failure model is described as follows [9]:

$$
\varepsilon_{\mathrm{f}}=\left(\mathrm{D}_{1}+\mathrm{D}_{2} \operatorname{EXP}\left(\mathrm{D}_{3}\left(\frac{\mathrm{P}}{\sigma_{\mathrm{y}}}\right)\right)\right)\left(1+\mathrm{D}_{4} \ln \dot{\varepsilon}\right)\left(1+\mathrm{D}_{5} \mathrm{~T}^{*}\right)
$$

In which $\frac{\mathrm{P}}{\sigma_{\mathrm{y}}}$ is stress triaxiality parameter and $\dot{\varepsilon}$ is strain rate. The constant $\mathrm{D}_{1}$ through $\mathrm{D}_{5}$ are material constants and obtained from experiment. The quantity describe by $\mathrm{D}=\sum \frac{\Delta \varepsilon}{\varepsilon_{\mathrm{f}}}$ called damage parameter is a function of strain rate and stress triaxiality coefficient. In this relationship $\Delta \varepsilon^{\mathrm{p}}=\frac{\sqrt{2}}{3}\left[\sum\left(\mathrm{d} \varepsilon_{1}-\mathrm{d} \varepsilon_{2}\right)^{2}\right]^{1 / 2}$ is the plastic strain increment in each repetition and $\varepsilon_{\mathrm{f}}$ is the fracture strain. When Damage parameter reaches unity failure will occur and the failed element will model. 


\subsection{Johnson-Cook Material Model}

In addition to material damage model, material model is also an essential requirement in any simulation of deformation. The model of most of metals depends on deformation temperature and strain rate. In 1983 Johnson and Cook using Hancock and Mackenzie experiments on variety of metals developed and experimental relationship which applications in numerical simulation of material behavior is expressed in the following $[10 ; 11]$ :

$$
\sigma=\left[\mathrm{A}+\mathrm{B} \varepsilon_{\mathrm{pl}}^{\mathrm{n}}\right]\left[1+\mathrm{C} \ln \varepsilon^{*}\right]\left[1-\mathrm{T}^{* \mathrm{~m}}\right]
$$

Where $\varepsilon_{\mathrm{pl}}$ is the effective plastic strain, $\stackrel{*}{\varepsilon}=\frac{\dot{\varepsilon}}{\varepsilon_{0}}$ is the dimensionless plastic strain rate for a reference strain rate, and $\mathrm{T}^{*}$ is a form of homologous temperature given as $\mathrm{T}^{*}=\frac{\left(\mathrm{T}-\mathrm{T}_{\text {room }}\right)}{\left(\mathrm{T}_{\text {melt }} \mathrm{T}_{\text {room }}\right)}$. The five material constants $\mathrm{A}, \mathrm{B}, \mathrm{C}, \mathrm{m}$, $\mathrm{n}$ are fit to data collected for a particular material.

Cook material model $(\mathrm{A}, \mathrm{B}, \mathrm{n})$ were obtained by fitting the stress-strain curve to the first term in the model. These are $\mathrm{A}=28, \mathrm{~B}=68, \mathrm{n}=1$.

\section{Finite Element Mesh and Geometry}

The material considered in this study is the $5182 \mathrm{H} 111$ Aluminium alloy, with length $\mathrm{L}=250 \mathrm{~mm}$ and the depth $\mathrm{D}=5 \mathrm{~mm}$ and the width $57 \mathrm{~mm}$. Finite element modeling is performed by assuming 3D deformation. The mechanical loading results from applying displacement traction at the outside extremity of the $5182 \mathrm{H} 111$ Aluminium alloy. The main mechanical and thermal Properties of tested specimen are summarized in Table1. The specimen's geometry is shown in Fig.3. Specimen is especially prepared for thermographic measurements. It is polished and cleaned to remove any oxide and grease.

To obtain a thermal stress loading under homogeneous uniform temperature distribution, the $5182 \mathrm{H} 111$ alloy was restrained against axial expansion by creating an interaction boundary condition at its outside edge (Figs. 4). In order to determine thermal strain in the analysis we have need to the thermal expansion coefficient $\alpha$ [12].Poisson's coefficient does not depend on temperature and takes the constant value $v=0.3$.

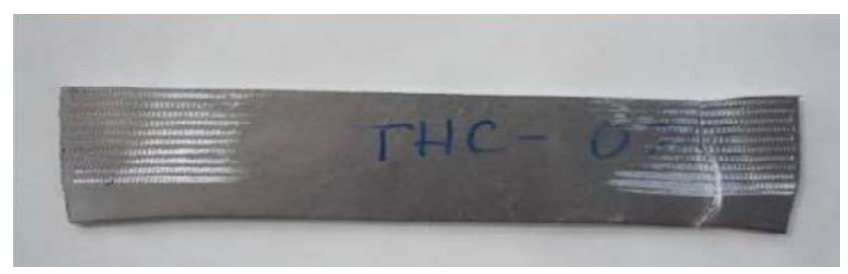

Figure 3. Geometry of the tested specimens $5182 \mathrm{H111}$ Aluminium alloy.
Table 1. Mechanical and thermal properties of the tested specimen.

\begin{tabular}{ll}
\hline Aluminium 5182 H111 & \\
\hline Tensile modulus MPa & 2700 \\
Tensile strength (Nmm-2) & 284 \\
Yield stress (MPa) & 154 \\
Mass thermal capacity (Jkg-1K-1) & 909 \\
Thermal conductivity (Wm-1K-1) & $209-232$ \\
\hline
\end{tabular}

\section{Loads}

A displacement boundary condition was applied to the grip end of the tensile specimen. The displacement was smoothly ramped up in the first portion of the test and then held constant as shown in Figure 4.

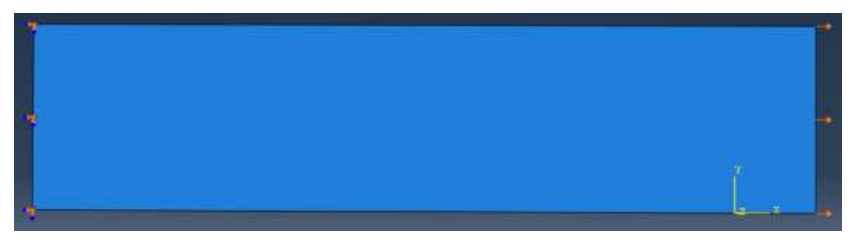

Figure 4. Load and boundary condition.

Fine meshes with $0.0012 \mathrm{~mm}$ elements and coarse meshes with $0.012 \mathrm{~mm}$ elements were used. The two meshes used are shown in (Figure 5).
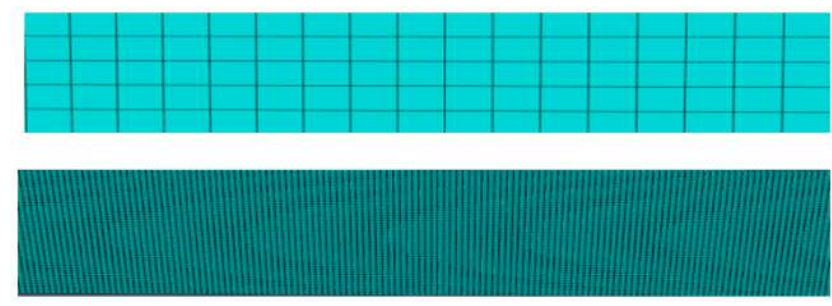

Figure 5. Fine meshes 0.012 (Upper) and coarse meshes 0.0012 (Lower).

\section{Mechanical Alanalysis of Numerical Simulation}

The output of the mechanical and thermal analysis is the deformation field and the temperature distribution during the mechanical cycling. An example is given in Fig. 6 and 7.
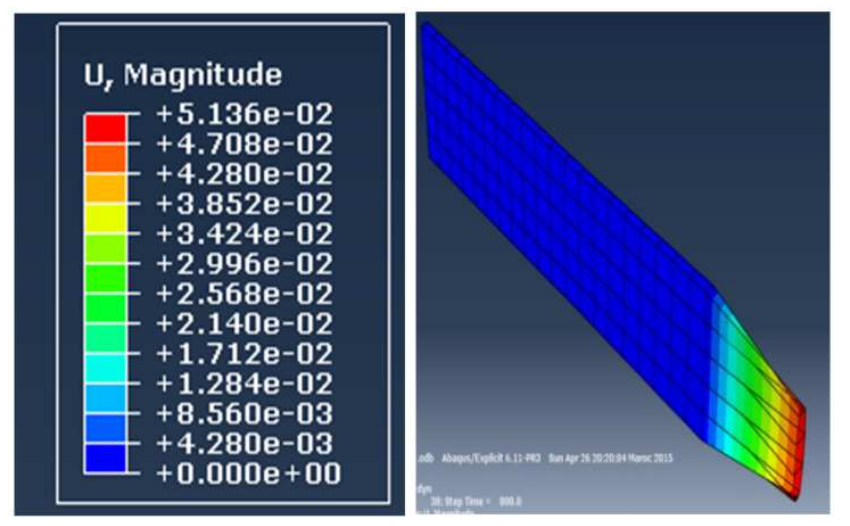

Figure 6. deformation field during loading test. 

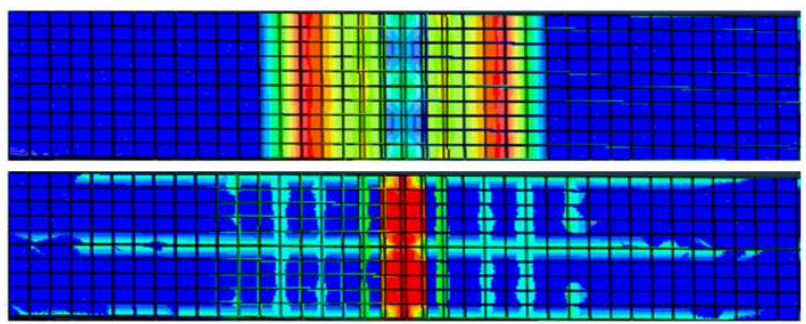

Figure 7. Temperature evolution images of the specimen during loading test.

Figure 7 shows the temperature distribution in the specimen during all time. The highest temperatures are found near the center of the specimen, which are caused by the high plastic deformation at this region.

\section{Results and Discussion}

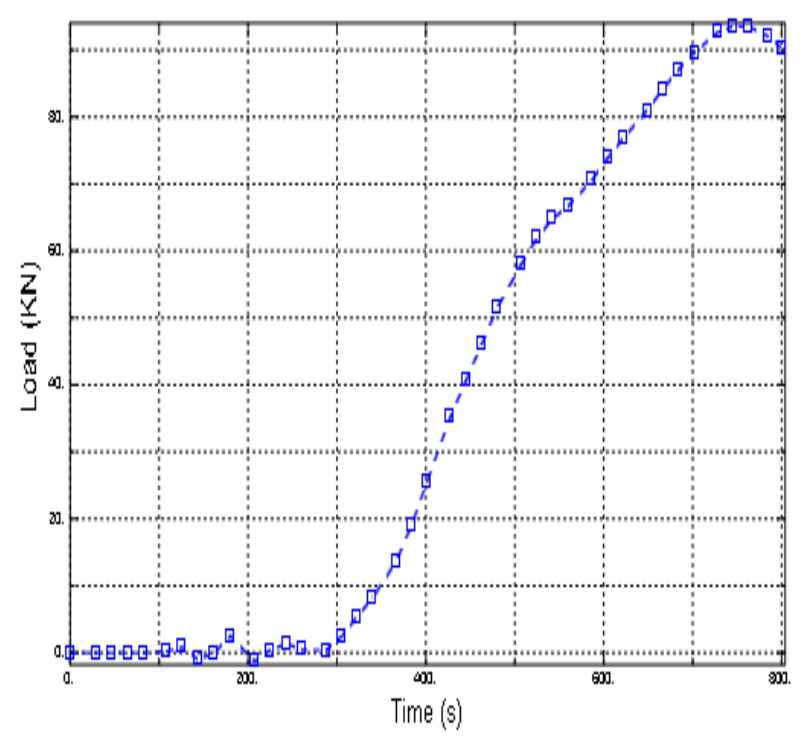

Figure 8. Load vs. time.

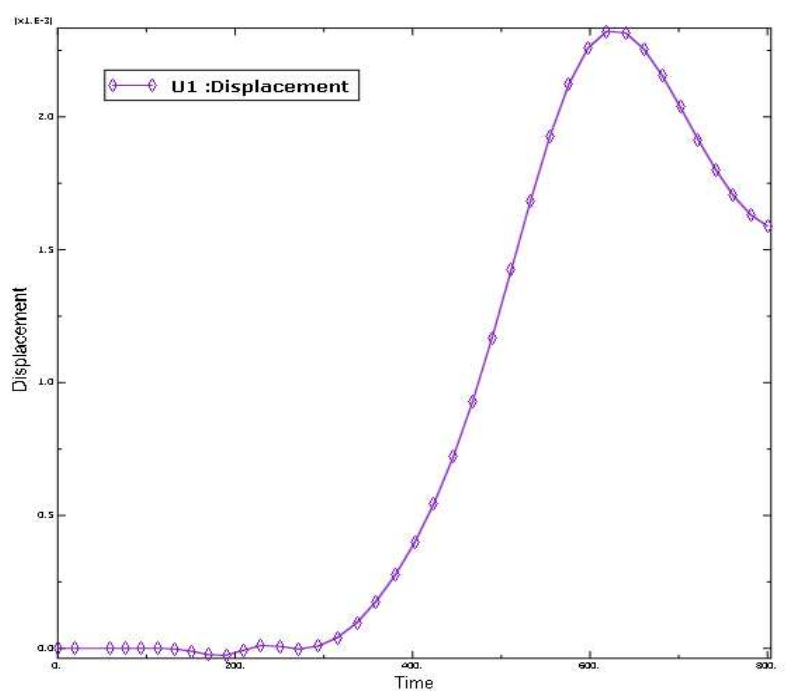

Figure 9. Elongation vs time.

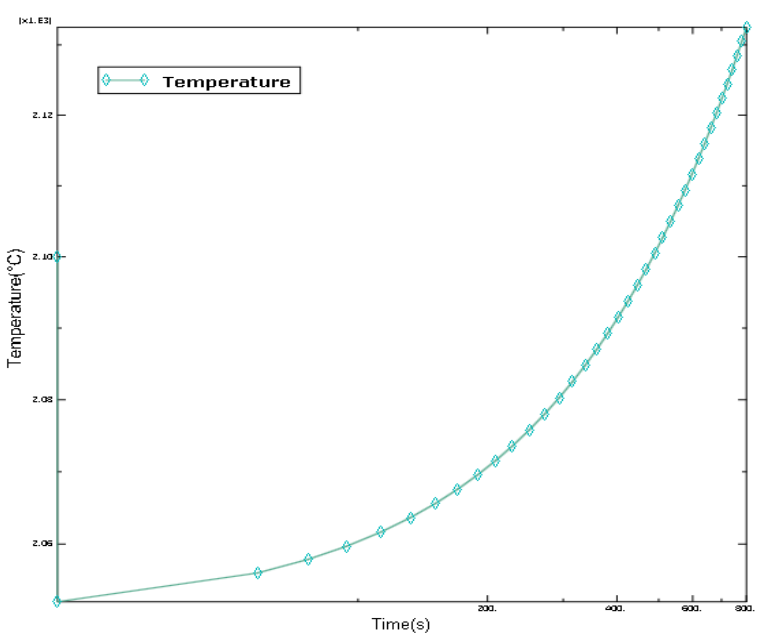

Figure 10. distribution temperature vs time.

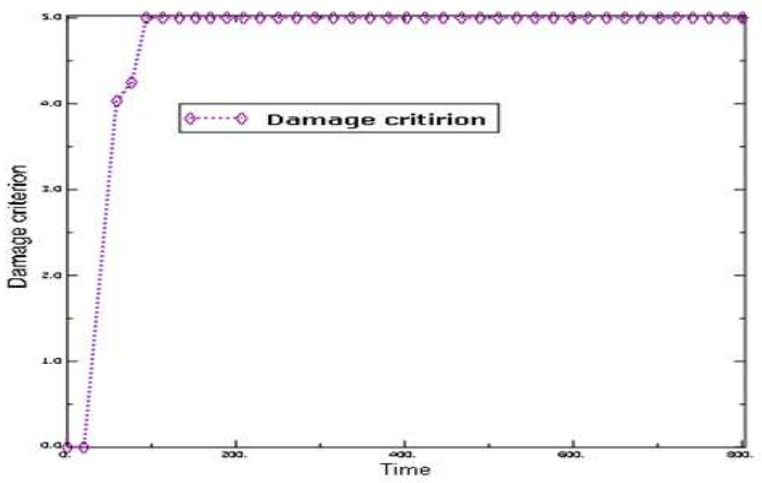

Figure 11. Damage criterion vs. elongation for the 5182 H111 Aluminium specimen.

The tensile behavior of the specimen was determined as the load-elongation relation during tensile loading. Furthermore, a change in the elongation during loading curve was obtained. Load start, i.e. elastic strain start, then plastic strain start point where the maximum force is reached, i.e. the end of homogenous plastic strain.

Figure 9 shows the evolution of the displacement on the surface of the specimen and that the maximum elongation before final failure line started. Thus, the failure does starting in this case because the plate reached the state of rupture. Figure 8 shows the load variation during time steps, the beginning of elastic deformation, the beginning of plastic deformation, reaching maximum force, the homogeneous plastic deformation to the final fracture of the specimen. The analysis of the results presented in Figs 8 show that in the first 350 seconds the force reaches $20 \mathrm{kN}$ The maximum tensile force is about $95 \mathrm{kN}$. The temperature increase with a constant gradient and the total elongation is $6 \mathrm{~mm}$ thus .

\section{Conclusion}

The Numerical results for the tensile properties of 5182 H111 Aluminium alloy, considered in this paper, indicate the fact that the testing of metal structures requires new contactless methods. The commercial finite element software 
ABAQUS simulation using the Johnson-Cook methods of fracture mechanics were applied due to the safety assessment of metal structures. The Numerical results prove that Johnson-Cook model offers the possibility of non-destructive and real time testing to observe the physical process of metal degradation and to detect the occurrence of energy dissipation. The obtained results confirm that it is very useful to use Johnson-Cook material model for early diagnostics of complex metal structures in the exploitation or service conditions.

\section{Acknowledgements}

The authors would like to acknowledgement, University polytechnic School of Mining and Industrial Engineering of Almaden, 1 Plaza Manuel Meca, 13400 Almaden, Spain.

\section{References}

[1] M. Abendroth, M.kuna, " determination of deformation and failure properties of ductile materials by means of the small punch test and neural networks", computational materials Science 28(2003) 633-644.

[2] V.vely,G.bernhart and L.penezzi,A.Persson and J.Bergström, 'thermal fatigue of tools steel: experiment and numerical simulation", 6 th international tooling conference.

[3] Bauvineau, L., Burlet, H., Eripret, C. and Pineau, A.: Modelling ductile stable crack growth in a CMn steel with local approaches, in: Proceedings of the first European Mechanics of Materials Conference on Local Approach to Fracture, 09- 11.09.1996, Fontainebleau, France, pp. 26-38.
[4] Bashir Younise, Marko Rakin, Bojan Medjo, Aleksandar Sedmak 'Numerical Simulation for Studying Constraint Effect on Ductile Fracture Initiation Using Complete Gurson Model" FME Transactions, 200 - VOL. 38, No 4, 2010.

[5] R.Kopp, M.L.Cao and M.M.Souza, 'Multi-level simulation of metal forming process", Proc. 2nd ITCP, Stuttgart, August 1987, pp.1128-1234.

[6] W.Johnson, "Developments in forming technology-an engineering educator's appoach", Journal of materials processing technology, vol.31, pp.1-26, 1992.

[7] F.Mata Cabrera, J.Tejero Manzanares, I.Hanafi, A.B.Arenas, I.Garrido, V.Toledano, M.L.Rubio, "Investigation the deformation and damage scenario under tensile loading of ductile specimens using thermography," Int.Rev.Appl.Sci.Eng.5(2014), 1,1-8.

[8] A. El-Azrab, M.Garnich, A.Kapoor,'Modeling of the electromagnetic forming of sheet metals: state - of-the-art and future needs",Journal of materials Processing technology, vol.142,2003,pp.744-754.

[9] Johnson GR, Cook W.H. Fracture characteristics of three metals subjected to various strains, strain rates, temperatures and pressures, Engng Fract Mech, 1985; 21: 31-48.

[10] Johnson G. R. \& Cook W.H., A constitutive model and data for metals subjected to large strain, high strain rate and high temperature, 7 th int. symp. Ballistics, pp.541-547,1983.

[11] Rafal olaf smerd, Constutivie behavior of aluminum alloy sheet at high strain rates, thesis Presented to the university waterloo, Ontario, Canada 2005 50th.

[12] Achraf Zineb, khamlichi Abdellatif, Francisco Mata Cabrera, '” Effects of cycle duration and phasing on thermomechanical Fatigue of Dog-Bone specimens Made form steel"American J. of Engineering and applied Sciences 3(4), 740-748,2010. 